compartment in patients with knee osteoarthritis (OA). While HTO permanently unloads the more affected compartment (MAC) by overcorrecting the leg axis, KJD temporarily unloads the whole joint by separating the tibia and femur for $5 \mathrm{~mm}$ for 6 weeks. In a previous randomized controlled trial (RCT), comparable clinical benefit and radiographic joint space width (JSW) increase over 2 years follow-up were demonstrated for both treatments ${ }^{1}$. Yet, comparison of JSW before and after HTO may be unreliable, as pseudo-widening of the unloaded compartment may occur due to the induced leg axis change. Therefore, direct cartilage thickness measurements need to be compared between KJD and HTO, to accurately evaluate the efficacy of both treatment options on cartilage structure.

Objectives: To compare two-year cartilage thickness changes after treatment with KJD vs HTO and identify factors predicting cartilage thickness restoration.

Methods: Patients indicated for HTO were randomized to KJD (KJD ${ }_{\text {HTO }}$ ) or HTO treatment. Patients indicated for total knee arthroplasty received KJD (KJD TKA $)$. Standardized semi-flexed weight-bearing radiographs and $3 T$ MRIs with 3D spoiled gradient recalled imaging sequence with fat suppression (SPGR-fs) were acquired before and two years after surgical treatment. Cartilage thickness in the knee was measured using Chondrometrics Works 3.0 software. On the radiographs the mean JSW in the MAC were measured with KIDA software. Readers were blinded to the type of intervention and acquisition order. The primary and secondary outcomes were the mean MAC cartilage thickness (ThCtAB) and percentage of denuded bone area ( $\mathrm{AABp}$ ) change before and two years after treatment $(\mathrm{MRI})$, with radiographic joint space width (JSW) used as a reference.

Results: No statistically significant differences in the baseline characteristics were seen between $\mathrm{KJD}_{\text {HTO }}(n=18)$ and HTO $(n=33)$. The $\mathrm{KJD}_{\text {TKA }}$ group $(n=18)$ had a higher age and Kellgren-Lawrence grade (KLG) than the HTO and KJD ${ }_{\text {HTO }}$ groups.

$\mathrm{KJD}_{\text {HTO }}$ patients did not show significant changes in MAC cartilage thickness, dABp, or JSW over time (all p>0.10; figure 1). HTO patients displayed a decrease in MAC cartilage thickness and an increase in $d A B p$ (both $p<0.03$ ), but an increase in JSW $(p=0.006)$. KJD ${ }_{\text {TKA }}$ showed a significant increase in MAC cartilage thickness and JSW and decrease in dABp (all $p<0.01$ ). Baseline OA severity was the strongest predictor of cartilage restoration. KJD patients with severe $O A\left(K J D_{\text {severe }} ; K L G \geq 3\right.$ ) showed significant restoration (all $p<0.01$; figure 2); mild OA patients $\left(\mathrm{KJD}_{\text {mild }} ; \mathrm{KLG} \leq 2\right)$ showed a slight deterioration. $\mathrm{KJD}_{\text {se }}$ showed a significantly greater cartilage restoration response in the MAC than $\mathrm{HTO}_{\text {severe }}$ for cartilage thickness $(p=0.005)$ and $d A B p(p=0.003)$, but not JSW change $(p=0.521)$. The changes in all three parameters did not differ significantly between $\mathrm{KJD}_{\text {mild }}$ and $\mathrm{HTO}_{\text {mild }}$ (all $\mathrm{p}>0.08$ ).

Conclusion: In patients with severe knee OA, KJD is more efficient in restoring cartilage thickness than HTO is. In these patients, KJD causes significant cartilage restoration while HTO, despite shifting the leg axis and demonstrating radiographic joint space widening, shows loss of cartilage as measured on MRI. In patients with mild knee OA, neither HTO nor KJD treatment results in significant cartilage restoration and both treatments show a slight deterioration that is likely the result of natural OA progression. As such, this research promotes the choice KJD as joint-preserving surgery in case of knee OA patients with more severe structural damage.

References:

[1] MP Jansen et al, Cartilage 2019.
A

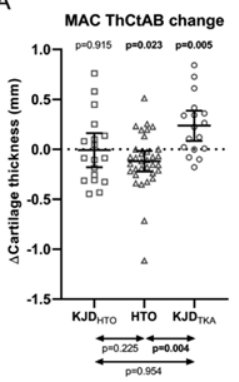

B

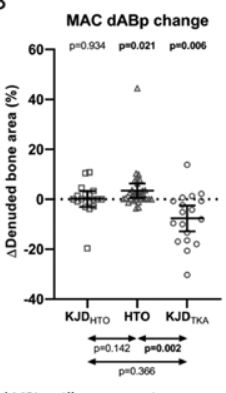

C

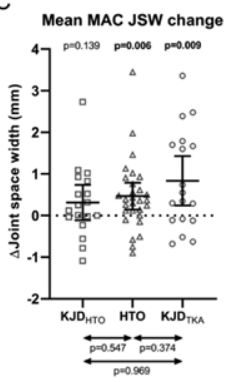

Figure 1: Two-year change in radiographic and MRI cartilage parameters.
(A) Change in MRI mean cartilage thickness over the total subchondral bone area (ThCtAB) of the most affected compartment (MAC), for the three groups: $\mathrm{KJ}$ wTo = KJD patients with indication high tibial osteotomy (HTO); KJDTrA $=$ knee joint distraction (KID) patients with indication total knee arthroplasty. (B) Change in MRI percentage of denuded subchondral bone area (dABp) of the MAC for the three groups. (C) Change in mean radiographic joint space width (ISW) of the MAC for the three groups. Markers represent individual patients, dashes represent the group mean and $95 \%$ confidence interval. P-values above groups

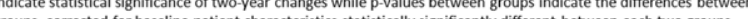
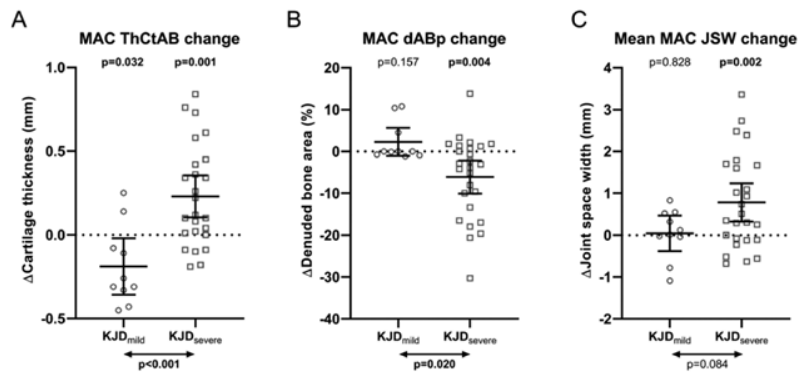

Figure 2: Two-year change in radiographic and MRI cartilage thickness parameters for knee joint distraction (KID) patients with mild (KID mila) and severe (KID severes) osteoarthritis.

(A) Change in MRI mean cartilage thickness over the total subchondral bone area (ThCtAB) of the most affected compartment (MAC). (B) Change in MRI percentage of denuded subchondral bone area (dABp) of the MAC for both groups. (C) Change in mean radiographic joint space width (ISW) of the MAC for both groups.

Markers represent individual patients, dashes represent the group mean and $95 \%$ confidence interval. P-values above groups Markers represent individual patients, dashes represent the group mean and $95 \%$ confidence interval. $P$-values above groups
indicate statistical significance of two-year changes while p-values between groups indicate the differences between each two
groups, corrected for statistically significantly different baseline characteristics.

Disclosure of Interests: Mylène Jansen: None declared, Susanne Maschek Shareholder of: Stock/stock options at Condrometrics $\mathrm{GmbH}$, Employee of: Employment at Condrometrics $\mathrm{GmbH}$, Ronald Van Heerwaarden: None declared, Simon Mastbergen: None declared, Wolfgang Wirth Shareholder of: Stock/stock options at Condrometrics $\mathrm{GmbH}$, Consultant of: Consultancy to Galapagos NV, Employee of: Employment at Condrometrics $\mathrm{GmbH}$, Floris Lafeber Shareholder of: Co-founder and shareholder of ArthroSave BV, Felix Eckstein Shareholder of: Stock/stock options at Condrometrics $\mathrm{GmbH}$, Consultant of: Consultancy at Merck KGaA, Samumed, Bioclinica, Galapagos, Servier, Novartis, Employee of: Employment at Condrometrics $\mathrm{GmbH}$, Speakers bureau: Development of educational presentations for Medtronic

DOI: 10.1136/annrheumdis-2020-eular.1319

\begin{tabular}{|l|l}
\hline OP0186 & HYDROXYCHLOROQUINE IN PATIENTS WITH \\
INFLAMMATORY AND EROSIVE OSTEOARTHRITIS OF \\
THE HANDS: RESULTS OF A RANDOMIZED, DOUBLE- \\
BLIND, PLACEBO CONTROLLED, MULTI-CENTRE, \\
INVESTIGATOR-INITIATED TRIAL (OA TREAT)
\end{tabular}

C. Kedor $^{1}$, J. Detert ${ }^{2}$, R. Rau ${ }^{3}$, S. Wassenberg ${ }^{3}$, J. Listing ${ }^{4}$, P. Klaus ${ }^{5}$, T. Braun ${ }^{1}$, W. Hermann ${ }^{6}$, S. Weiner ${ }^{7}$, M. Bohl-Bühler ${ }^{8}$, F. Buttgereit ${ }^{1}$, G. R. Burmester ${ }^{1}$. ${ }^{1}$ Charité - Universitätsmedizin Berlin, Berlin, Germany; ${ }^{2}$ Rheuma-Templin, Templin, Germany; ${ }^{3}$ Rheumazentrum Ratingen, Ratingen, Germany; ${ }^{4}$ Deutsches Rheuma-Forschungszentrum (DRFZ), Berlin, Germany; ${ }^{5}$ Pfizer Pharma GmbH, Berlin, Germany; ${ }^{6}$ Kerckhoff-Klinik, Bad Nauheim, Abteilung Rheumatologie, Bad Nauheim, Germany; ${ }^{7}$ Krankenhaus der Barmherzigen Brüder, Trier, Germany; ${ }^{8}$ Rheumahaus, Potsdam, Germany

Background: Hand osteoarthritis $(\mathrm{OA})$ is a very common condition with cartilage degradation and frequently erosive bone changes. It may be very painful and can greatly affect everyday activities. Common analgesics and NSAIDs are used for symptomatic relief but are often poorly tolerated or contraindicated especially in elderly patients. There is no effective and proven disease modifying therapy available. Previous publications and anecdotal reports suggest hydroxychloroquine (HCQ) as a possible treatment, and some physicians use HCQ off-label for the treatment of $O A$

Objectives: To investigate the efficacy and safety of HCQ in patients with inflammatory and erosive hand $\mathrm{OA}$ in a randomized, double-blind, placebo controlled, multi-centre, investigator-initiated trial

Methods: Patients with inflammatory and erosive hand OA, according to the ACR criteria, with radiographically proven erosive disease were randomized $1: 1$ to $\mathrm{HCQ} 200-400 \mathrm{mg}$ per day or matching placebo (PBO) for 52 weeks. Both groups received standard therapy (stable NSAIDs). The primary endpoint was AUSCAN for pain and hand disability at week 52 (W52). A secondary endpoint was radiographic progression from baseline (BL) to W52. A multiple endpoint test and analysis of covariance was used to compare changes between groups. All analyses were conducted on an intention-to-treat base

Results: Of 156 patients 3 were excluded and 75 were randomized to HCQ and 78 to PBO. Mean age was 52.4 (SD 8.1) in the HCQ and 50.2 (SD 6.6) years in the PBO group. $68(90.7 \%)$ of the patients were female in the HCQ and 60 $(76.9 \%)$ in the PBO group. Disease duration was 9.5 (SD 7.5) in HCQ and 10.8 (SD 8.8) years in PBO group. CRP and ESR were normal in both groups. BL pain (AUSCAN) was 31.1 (SD 8.2) and 30.7 (SD 8.9), BL function (AUSCAN) was 58.5 (SD 15.5) in HCQ and 57.8 (SD 17.1) in PBO patients. Table 1 shows clinical and functional parameters at W52. Only morning stiffness was significantly reduced in the HCQ group $(p=0.001)$. Changes in radiographic scores did not 
differ significantly $(p>0.05)$ between treatment groups. There were 7 SAE in the $\mathrm{HCQ}$ and 15 in the PBO group. No new safety issues were detected

Table 1. Results of the covariance analysis (ANCOVA)-adjusted mean values and $95 \%$-confidence intervals for primary and secondary outcomes at W52, as well as a p-value for group comparison

\begin{tabular}{lccccccc}
\hline Outcome & $\begin{array}{c}\text { Adj. Mean } \\
\text { HCQ }\end{array}$ & $\begin{array}{c}95 \%-\mathrm{Cl} \\
\mathrm{HCQ}\end{array}$ & $\begin{array}{c}\text { Adj. Mean } \\
\text { PBO }\end{array}$ & $\begin{array}{c}95 \%-\mathrm{Cl} \\
\text { PBO }\end{array}$ & $\begin{array}{c}\text { P-value } \\
\mathrm{HCQ} \times \text { PBO }\end{array}$ \\
\hline AUSCAN Function & 48.1 & 43 & 53.3 & 51.3 & 46.6 & 56 & 0.36 \\
AUSCAN Pain & 26.7 & 23.9 & 29.4 & 26.5 & 23.9 & 29.1 & 0.92 \\
tender joint & 6.4 & 4.8 & 7.9 & 7.1 & 5.4 & 8.7 & 0.49 \\
swollen joint & 2 & 1.3 & 2.7 & 2.1 & 1.4 & 2.7 & 0.93 \\
ESR (mm/h) & 8.2 & 6.9 & 9.6 & 11.7 & 10.1 & 13.5 & $<0.01$ \\
HAQ & 0.9 & 0.8 & 1 & 0.8 & 0.7 & 0.9 & 0.46 \\
Phys. Global & 3.2 & 2.8 & 3.6 & 3.5 & 3 & 3.9 & 0.39 \\
Pat. Global & 4.5 & 3.9 & 5.1 & 5.2 & 4.6 & 5.8 & 0.14 \\
SF36 mental & 48.8 & 46.6 & 51 & 50.8 & 48.7 & 52.8 & 0.22 \\
SF36 physical & 39.8 & 38 & 41.6 & 39.9 & 38.2 & 41.6 & 0.95 \\
Morning Stiffness (min) & 30.2 & 24 & 36.3 & 16.3 & 10.3 & 22.3 & 0.001 \\
Modif. Kallmann Score & 53.6 & 52.1 & 55.1 & 52.8 & 51.4 & 54.2 & 0.24 \\
\hline
\end{tabular}

The associated $B L$ value or, if available, a mean value from $B L$ and screening was included in the ANCOVA model as a covariate.

Conclusion: The OATREAT trial examined the clinical and radiological efficacy and safety of $\mathrm{HCQ}$ as a treatment option for inflammatory and erosive OA over 52 weeks. OATREAT is the first large randomized PBO controlled trial focusing on erosive hand $\mathrm{OA}$. HCQ was no more effective than PBO for changes in pain, function and radiographic scores in the 52-week period. Overall safety findings were consistent with the known profile of $\mathrm{HCQ}$. Thus, our data failed to show that $\mathrm{HCQ}$ is effective in patients with inflammatory, erosive hand $O A$

Disclosure of Interests: Claudia Kedor Consultant of: Advisory Board for Novartis Pharma GmbH, Jacqueline Detert: None declared, Rolf Rau: None declared, Siegfried Wassenberg: None declared, Joachim Listing: None declared, Pascal Klaus Employee of: Pfizer Pharma GmbH, Tanja Braun: None declared, Walter Hermann: None declared, Stefan Weiner: None declared, Martin Bohl-Bühler: None declared, Frank Buttgereit Grant/research support from: Amgen, BMS, Celgene, Generic Assays, GSK, Hexal, Horizon, Lilly, medac, Mundipharma, Novartis, Pfizer, Roche, and Sanofi., Gerd Rüdiger Burmester Consultant of: AbbVie Inc, Eli Lilly, Gilead, Janssen, Merck, Roche, Pfizer, and UCB Pharma, Speakers bureau: AbbVie Inc, Eli Lilly, Gilead, Janssen, Merck, Roche, Pfizer, and UCB Pharma

DOI: 10.1136/annrheumdis-2020-eular.819

\section{OP0187 DETERMINING OPTIMAL COOLING AND ADMINISTRATION METHODS FOR CNTX-4975 INTRA-ARTICULAR INJECTION IN SUBJECTS WITH MODERATE TO SEVERE OSTEOARTHRITIS KNEE PAIN}

R. Stevens ${ }^{1}$, P. Hanson ${ }^{1}$, P. Tiseo ${ }^{1}$, K. Guedes ${ }^{1}$, J. Campbell ${ }^{1}$, J. Connolly ${ }^{1}$, S. Ruggiero ${ }^{1}$, M. Corliss ${ }^{1}$, V. Smith ${ }^{2}$, P. G. Conaghan ${ }^{3} .{ }^{1}$ Centrexion Therapeutics Corp, Boston, United States of America; ${ }^{2}$ Premier Research, Durham, United States of America; ${ }^{3}$ University of Leeds, West Yorkshire, United Kingdom

Background: CNTX-4975 is a highly purified, synthetic capsaicin being developed to provide long-term analgesia after a single intra-articular (IA) injection for patients with moderate to severe osteoarthritis (OA) knee pain. CNTX-4975 IA administration is associated with short-term post-procedural pain that can be attenuated with preemptive joint cooling.

Objectives: To evaluate cooling and administration procedures for CNTX-4975 IA injection, with goals of balancing patient comfort and ease of use and assessing clinical response 8 weeks after injection.

Methods: This phase 3, open-label, 8-week study (NCT03661996) enrolled subjects aged 40-95 y with Kellgren-Lawrence grade $1-4$, BMI $\leq 45 \mathrm{~kg} / \mathrm{m} 2$, and stable, moderate to severe OA knee pain and who failed $\geq 2$ therapies. Subjects were assigned to unilateral/bilateral CNTX-4975 $1 \mathrm{mg}$ IA injections as determined by OA pain/joint replacement status, then randomized by study site to 1 of 5 treatment regimens (Figure). The primary outcome measure assessed Breg cooling control vs other cooling regimens on day 1 using a combined sum of 1 ) pain (0, none; 4 , severe) 30 minutes after CNTX-4975 injection; 2) subject satisfaction (SS) with cooling/injection procedures; and 3) investigator satisfaction (IS) with procedures. SS and IS were measured on a 1-7 scale (1, completely dissatisfied; 7, completely satisfied); pain was reverse scored and normalized (1, severe; 7, none) for equal weighting. Geometric mean ratios (GMR) with $95 \%$ Cls were constructed for each regimen vs Breg control (ANCOVA); lower 95\% $\mathrm{CI}>0.7$ was considered clinically acceptable. Secondary endpoints included percentage of subjects by subject type meeting criteria for Outcome Measures in Rheumatology-Osteoarthritis Research Society International (OMER ACT-OARSI) responders 8 weeks after injection. Safety assessments included TEAEs.

Results: The intent-to-treat population included 848 subjects. The primary combined outcome showed that all cooling and administration regimens were clinically acceptable, with the evaluated cold gel wraps being at least as effective as the Breg circulating ice-water wrap (Table). For subjects with unilateral OA OMERACT-OARSI response rates were $67 \%$ in those with no/mild nonindex knee pain and $81 \%$ in those with nonindex knee single joint replacement. For subjects with bilateral knee OA receiving bilateral injections, response rates for index and nonindex knees were $73 \%$ and $79 \%$. TEAEs were reported in $22 \%$ of subjects; $<1 \%$ were serious. TEAEs occurring in $>2 \%$ of subjects were procedural pain $(2.9 \%)$, arthralgia $(2.2 \%)$, and nausea $(2.1 \%)$, with no meaningful differences across groups.

Conclusion: All cooling regimens for CNTX-4975 IA administration were clinically acceptable and well tolerated, offering feasible options for use in routine practice. Importantly, high levels of clinical response were observed 8 weeks after unilateral or bilateral knee injections for moderate to severe OA knee pain.

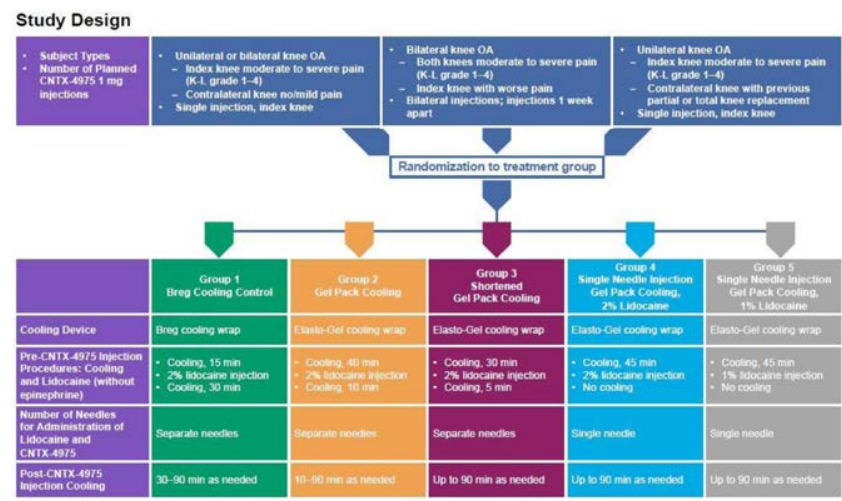

Primary Combined Endpoint Outcome in the Index Knee, Normalized Scale, by Cooling and Administration Procedure (ANCOVA Model)

\begin{tabular}{|c|c|c|c|c|c|}
\hline & $\begin{array}{c}\text { Breg } \\
\text { Cooling } \\
\text { Control } \\
\mathrm{N}=162\end{array}$ & $\begin{array}{c}\text { Gel Pack } \\
\text { Cooling } \\
\mathrm{N}=179\end{array}$ & $\begin{array}{c}\text { Shortened } \\
\text { Gel Pack } \\
\text { Cooling } \\
\mathrm{N}=175\end{array}$ & $\begin{array}{l}\text { Single Needle } \\
\text { Injection, } \\
\text { Gel Pack } \\
\text { Cooling, } \\
2 \% \text { Lidocaine } \\
\text { N=160 }\end{array}$ & $\begin{array}{l}\text { Single Needle } \\
\text { Injection, } \\
\text { Gel Pack } \\
\text { Cooling, } \\
1 \% \text { Lidocaine } \\
\mathrm{N}=172\end{array}$ \\
\hline Mean (SD) & $17.23(2.660)$ & $18.23(2.023)$ & $16.81(2.891)$ & 17.57 (3.049) & $16.43(3.138)$ \\
\hline $\begin{array}{l}\text { Geometric LS } \\
\text { Mean (SE) }\end{array}$ & $17.18(1.016)$ & $18.26(1.015)$ & $16.48(1.016)$ & $17.40(1.016)$ & $16.00(1.015)$ \\
\hline $\begin{array}{l}95 \% \mathrm{Cl} \\
\text { Comparison vs }\end{array}$ & $\begin{array}{r}16.66,17.72 \\
\text { Breg Cooling }\end{array}$ & $17.74,18.80$ & $15.99,16.99$ & $16.87,17.95$ & $15.53,16.49$ \\
\hline GMR (SE) & & 1.06 (1.022) & $0.96(1.022)$ & 1.01 (1.022) & $0.93(1.022)$ \\
\hline $95 \% \mathrm{Cl}$ & & $1.02,1.11$ & $0.92,1.00$ & $0.97,1.06$ & $0.89,0.97$ \\
\hline $\begin{array}{l}\text { Clinically } \\
\text { Acceptable? }\end{array}$ & & Yes & Yes & Yes & Yes \\
\hline
\end{tabular}

LS, least squares; SD, standard deviation; SE, standard error.

GMR lower $95 \% \mathrm{Cl}>0.7$ considered clinically equivalent.

Disclosure of Interests: Randall Stevens Shareholder of: Centrexion Therapeutics Corp, Employee of: Centrexion Therapeutics Corp, Peter Hanson Shareholder of: Centrexion Therapeutics Corp, Employee of: Centrexion Therapeutics Corp, Paul Tiseo Employee of: Centrexion Therapeutics Corp, Kimberly Guedes Shareholder of: Centrexion Therapeutics Corp, Employee of: Centrexion Therapeutics Corp, James Campbell Shareholder of: Centrexion Therapeutics Corp, Employee of: Centrexion Therapeutics Corp, James Connolly Employee of: Centrexion Therapeutics Corp, Stephanie Ruggiero Employee of: Centrexion Therapeutics Corp, Meg Corliss Employee of: Centrexion Therapeutics Corp, Valerie Smith Consultant of: Centrexion Therapeutics Corp, Philip G Conaghan Consultant of: AbbVie, BMS, Eli Lilly, EMD Serono, Flexion Therapeutics, Galapagos, GSK, Novartis, Pfizer, Speakers bureau: AbbVie, Eli Lilly, Novartis, Pfizer

DOI: 10.1136/annrheumdis-2020-eular.2200 